Article

\title{
Highly Efficient One-Pot Synthesis of 2,4-Disubstituted Thiazoles Using Au(I) Catalyzed Oxidation System at Room Temperature
}

\author{
Gongde Wu, Xiaoli Wang * and Hao Liu \\ Department of Environment and Technology, Nanjing Institute of Technology, Nanjing 211167, China; \\ wugongde@njit.edu.cn (G.W.); liuhao@163.com (H.L.) \\ * Correspondence: wangxiaoli212@njit.edu.cn; Tel./Fax: +86-25-8611-8960
}

Academic Editor: Xiao-Feng $\mathrm{Wu}$

Received: 25 July 2016; Accepted: 15 August 2016; Published: 20 August 2016

\begin{abstract}
In the present work, gold complex catalysts with Mor-DalPhos ligands were successfully prepared using mesylates as counter ions. Seven ammonium sulfonates were synthesized to promote the production of intermediate sulfonyloxymethyl ketone. It was found that low-acidity $N, N$-dimethylbenzenaminium methanesulfonate showed excellent activity in the reaction. Furthermore, the catalysts effectively avoided the loss of activity due to the low acidity. Various thioamides were directly added to the resulting reaction mixture without the separation of intermediate product. Then, twenty kinds of 2,4-disubstituted thiazoles were efficiently synthesized at room temperature with the highest yield of $91 \%$. This work provides an efficiency and mild gold-catalyzed oxidation system for the one-pot synthesis of thiazole and its derivatives.
\end{abstract}

Keywords: thiazole; terminal alkyne; thioamide; $\mathrm{Au}(\mathrm{I})$ complexes; ammonium sulfonate

\section{Introduction}

Thiazole is an aromatic, five-membered heteroaromatic compound containing both a nitrogen and a sulfur atom. This special thiazole ring structure endows thiazoles with wide application in chemical, pharmaceutical, biological, and material sciences, etc. [1-9]. It was the derivatives of 2,4-disubstituted thiazole that acted as active ingredient in many bioactive natural products and pharmaceuticals, such as mycothiazole, sanguinamide B, and archazolid A (Figure 1) [5,6]. Much effort has been put into the preparation of thiazole compounds, which became a much-talked-about topic in recent years [10,11].

In the past two decades, homogenous gold complexes were gradually believed to be an active catalyst, and it had been used in many reactions, such as forming reactions for $\mathrm{C}-\mathrm{C}$ and $\mathrm{C}-\mathrm{O}$ bonds, hydrogenation, and oxidation [12,13]. Noticeably, various gold catalysts with different ligands and counter anions showed high efficiency in the activation of a $\mathrm{C}-\mathrm{C}$ triple bond in alkyne via nucleophilic addition. Cationic phosphine $\mathrm{Au}(\mathrm{I})$ species were found to be excellent catalysts in the addition of alcohols to alkynes in 1998 [14]. Subsequently, gold(III) complexes were investigated as catalysts and used in the synthesis of five-membered rings with two heteroatoms [15-18]. Several years later, $\mathrm{R}_{3} \mathrm{PAuX}$ ( $X=$ trifluoromethanesulphonate, $\mathrm{OTf}^{-}$) or other weakly coordinating counter ions) demonstrated excellent catalytic performance in Conia-ene [19,20] and hydroarylation [21-23] reactions, as well as several carbon-heteroatom bond-forming reactions [24-26]. Recently, Zhang's group designed a new complex with the ligand (1,1'-biphenyl)-2-ylphosphine, which was found to be effective in the reaction of acid and alkynes with a turnover number up to 99,000 [27]. In previous articles, we also reported gold complexes with Mor-Dalphos ligands, which show excellent catalytic performance in the synthesis of 2,4-disubstituted thiazoles from terminal alkynes and thioamides [10,11]. However, highly-acidic $\mathrm{MsOH}$ or Zinc salt were employed in the catalytic systems, and the oxidant of 8-Me-quinoline $N$-oxides had to be added slowly by syringe pump with specific molar ratio. 


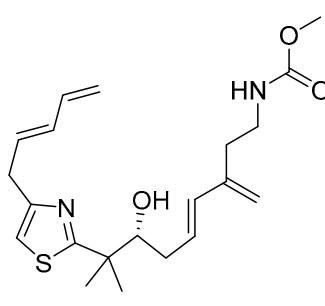

Mycothiazole

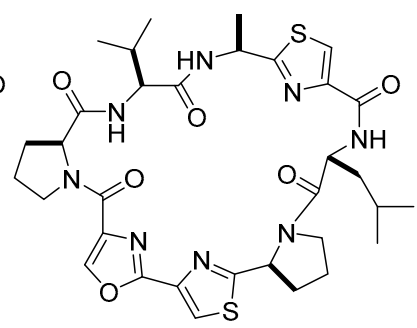

Sanguinamide $B$

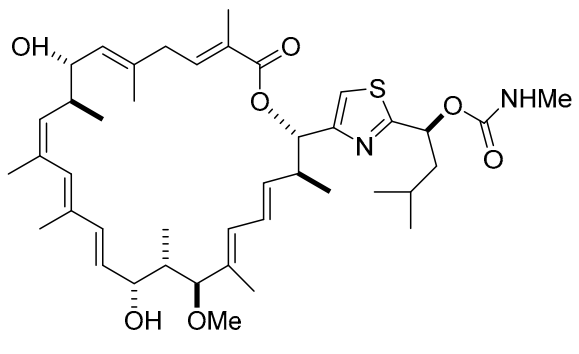

Archazolid $\boldsymbol{A}$

Figure 1. The structure of mycothiazole, sanguinamide B, and archazolid A.

In this work, seven low-acidity ammonium sulfonates were used for the source of $\mathrm{MsO}^{-}$in the catalytic oxidation of terminal alkynes into a sulfonyloxymethyl ketone intermediate. Except for thioamides, other substrates were added into the reactor by one time. The system employing $\mathbf{A}$ ( $\mathrm{N}, \mathrm{N}$-dimethylbenzenaminium methanesulfonate) was found to be an optimized reaction system for the synthesis of various 2,4-disubstituted thiazoles. Moreover, reaction conditions, catalyst types, and solvents-which played important roles in catalytic result-were also investigated in detail.

\section{Results and Discussion}

\subsection{Optimized Synthesis of Intermediate Product $2 a$}

The effect of gold catalysts, solvents, and ammonium sulfonates on reaction results is listed in Table 1. It can be seen that Mor-DalPhosAuCl exhibited the good yield of $58 \%$ with the presence of $\mathrm{AgNTf}_{2}$, and Me-DalPhosAuCl showed the slightly inferior yield of $53 \%$, due to the steric size of the pendant secondary amine [28]. These prospective results were consistent with our previous works, which further supported the accepted viewpoint that P,N-bidentate ligands could attenuate the strong electrophilicity of the a-oxo gold carbene via the formation of a tricoordinated metal center $[29,30]$. $\mathbf{L} \mathbf{A u C l}$ and $\mathbf{L} 2 \mathrm{AuCl}$, with the more rigid cyclic structure, displayed less-efficient yield in this reaction. Similarly, lower yields were obtained over the catalysts of $\mathbf{L} 3 \mathrm{AuCl}$ and $\mathrm{L} 4 \mathrm{AuCl}$, due to larger steric hindrance in comparison with Mor-DalPhosAuCl. The catalytic results from $\mathrm{L} 5 \mathrm{AuCl}$ to $\mathrm{L8AuCl}$ (entries 7 to 10) suggested that the gold complexes containing the (1,10-biphenyl)-2-ylphosphine framework were inefficient in this reaction. However, the yield was only $28 \%$ using high acid $\mathrm{MsOH}$ for the generation of intermediate product (entry 11). When $\mathrm{AgNTf}_{2}$ was replaced by AgOMs for gold catalysts, the exciting yield of $68 \%$ was obtained in the catalytic system of Mor-DalPhosAuCl/AgOMs (entry 12). Moreover, the prepared catalyst of Mor-DalPhosAuOMs showed the higher yield of $74 \%$ (entry 13). This result might be ascribed to the spatial proximity between $\mathrm{MsO}^{-}$and 2a [11]. In addition, eight different solvents were selected to investigate the effect of solvent on the catalytic performance. To our delight, the yield increased to $82 \%$ when dichloromethane (DCM) was used. The seven as-prepared ammonium sulfonates were also investigated. The results show that 2 yield decreased over the structure of ammonium sulfonates: $\mathrm{A}>\mathrm{E}>\mathrm{B} \approx \mathrm{C}>\mathrm{F}>\mathrm{D}>\mathrm{G}$. It can be seen that $\mathrm{A}$ displayed the highest reaction activity due to the minimum steric hindrance. At the same time, all of the $\mathrm{N}, \mathrm{N}$-Dimethylamiline sulfonic salts exhibited higher activity than that of $N, N$-Diethylaniline sulfonic 
salts due to less steric hindrance. Additionally, methaneammonium sulfonates $G$ showed the lowest yield of $43 \%$ in the presence of the $\mathrm{Br}^{-}$electron withdraw group. Therefore, $\mathbf{A}$, Mor-DalPhosAuOMs, and DCM were chosen as the optimum reaction factors for the synthesis of $\mathbf{2 a}$ in the following research (Scheme 1).

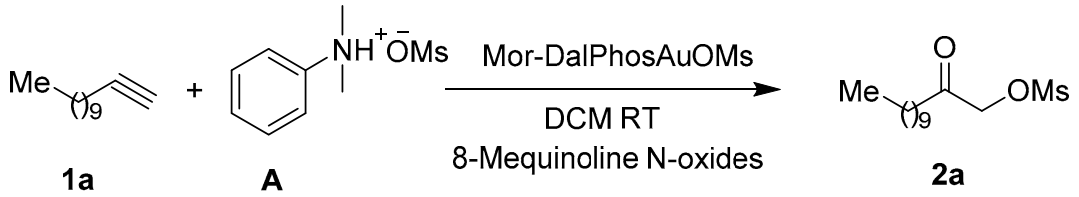

Scheme 1. The preparation of intermediate product 2a.

Table 1. Screening gold catalysts, solvents, and ammonium sulfonates ${ }^{a}$.

\begin{tabular}{|c|c|c|c|c|}
\hline & (A) & 6), rt, $6 \mathrm{~h}$ & G & \\
\hline Entry & Catalysts & Salts & Solvent & 2 Yield $^{b}(\%)$ \\
\hline 1 & Me-DalPhosAuCl/AgNTf 2 (5 mol \%) & A & DCE & 53 \\
\hline 2 & Mor-DalPhosAuCl/ $\mathrm{AgNTf}_{2}(5 \mathrm{~mol} \%)$ & A & DCE & 58 \\
\hline 3 & $\mathbf{L 1} \mathrm{AuCl} / \mathrm{AgNTf}_{2}(5 \mathrm{~mol} \%)$ & A & DCE & 47 \\
\hline 4 & $\mathrm{~L}_{2} \mathrm{AuCl} / \mathrm{AgNTf}_{2}(5 \mathrm{~mol} \%)$ & A & DCE & 21 \\
\hline 5 & L3AuCl/ $\mathrm{AgNTf}_{2}(5 \mathrm{~mol} \%)$ & $\mathrm{A}$ & DCE & 43 \\
\hline 6 & $\mathrm{~L}_{4} \mathrm{AuCl} / \mathrm{AgNTf}_{2}(5 \mathrm{~mol} \%)$ & A & DCE & 32 \\
\hline 7 & L5AuCl/ $\mathrm{AgNTf}_{2}(5 \mathrm{~mol} \%)$ & A & DCE & 16 \\
\hline 8 & $\mathrm{~L} \mathrm{AuCl} / \mathrm{AgNTf}_{2}(5 \mathrm{~mol} \%)$ & A & DCE & 19 \\
\hline 9 & 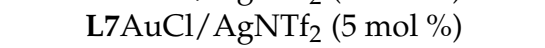 & A & DCE & 22 \\
\hline 10 & $\mathrm{~L} \mathrm{AuCl} / \mathrm{AgNTf}_{2}(5 \mathrm{~mol} \%)$ & A & DCE & 26 \\
\hline 11 & Mor-DalPhosAuCl/ $\mathrm{AgNTf}_{2}(5 \mathrm{~mol} \%)$ & $\mathrm{MsOH}$ & DCE & 28 \\
\hline 12 & Mor-DalPhosAuCl/AgOMs (5 mol \%) & A & DCE & 68 \\
\hline 13 & Mor-DalPhosAuOMs & A & DCE & 74 \\
\hline 14 & Mor-DalPhosAuOMs & A & DCM & 82 \\
\hline 15 & Mor-DalPhosAuOMs & A & THF & 36 \\
\hline 16 & Mor-DalPhosAuOMs & A & Fluorobenzene & 76 \\
\hline 17 & Mor-DalPhosAuOMs & A & $\mathrm{MeCN}$ & 41 \\
\hline 18 & Mor-DalPhosAuOMs & A & Toluene & 56 \\
\hline 19 & Mor-DalPhosAuOMs & $\mathrm{A}$ & Trifluoromethyl-benzene & 67 \\
\hline 20 & Mor-DalPhosAuOMs & A & Choloride benzene & 61 \\
\hline 21 & Mor-DalPhosAuOMs & B & DCM & 72 \\
\hline 22 & Mor-DalPhosAuOMs & C & DCM & 72 \\
\hline 23 & Mor-DalPhosAuOMs & $\mathrm{D}$ & DCM & 70 \\
\hline 24 & Mor-DalPhosAuOMs & E & DCM & 75 \\
\hline 25 & Mor-DalPhosAuOMs & $\mathrm{F}$ & DCM & 72 \\
\hline 26 & Mor-DalPhosAuOMs & G & DCM & 43 \\
\hline
\end{tabular}

a Reaction condition: 1-dodecyne, $0.25 \mathrm{mmol}$; Ammonium sulfonates, 1.2 eq.; Oxidants, 1.2 eq.; DCM $0.5 \mathrm{~mL}$; Room temperature $\left(25^{\circ} \mathrm{C}\right) ; 6 \mathrm{~h}$; Catalysts, $5 \%$ mmol. ${ }^{\mathrm{b}}$ Measured by ${ }^{1} \mathrm{H}$ NMR using diethyl phthalate as the internal standard. 
In order to obtain the optimized catalytic performance, the ratio of substrates, amount of catalyst, and reaction scale were intensively investigated at room temperature in $6 \mathrm{~h}$ (Figure 2). Firstly, Figure 2a displays the effect of $\mathbf{A} / 1$-dodecyne molar ratio on reaction results when $5 \mathrm{mmol} 1$-dodecyne, $1.2 \mathrm{eq}$. oxidants, $5 \mathrm{~mL} \mathrm{DCM}$, and $5 \%$ mol catalyst were used. It was found that a $2 \mathrm{a}$ yield of $80 \%$ was obtained with 1.2 molar ratio of A/1-dodecyne. During the course of the reaction in Scheme 2, it was $\mathrm{OMs}^{-}$that reacted with intermediate $\mathbf{H}$ to afford intermediate $\mathbf{I}$. The concentration of $\mathrm{OMs}^{-}$play an important role in the generation of intermediate $\mathbf{I}$, and the reaction would be accelerated by a high concentration of $\mathrm{OMs}^{-}$. It was well known that there is an ionic equilibrium between the ammonium sulfonate and $\mathrm{OMs}^{-}$. More $\mathrm{OMs}^{-}$would be produced with the presence of more ammonium sulfonate. So, 1.2 eq. of ammonium sulfonate was employed in the catalytic system. However, with the increasing of the molar ratio in excess, 2a yield decreased sharply because the catalyst partly lost activity due to an excess of $\mathbf{A}$. Then, the effect of oxidant/1-dodecyne molar ratio on the catalytic performance was also investigated when $5 \mathrm{mmol} 1$-dodecyne, 1.2 eq. A, $5 \mathrm{~mL} \mathrm{DCM}$, and $5 \% \mathrm{~mol}$ catalyst were used (see Figure $2 \mathrm{~b}$ ). It was suggested that $2 \mathbf{a}$ yield increased with the increasing of oxidant/1-dodecyne molar ratio up to 1.2. However, with the further increasing of oxidant, the 2a yield decreased remarkably because catalyst was poisoned by excess oxidant. Figure $2 \mathrm{c}$ shows that the dosage of catalyst obviously affects 2 a yield when 5 mmol 1-dodecyne, 1.2 eq. oxidants, $5 \mathrm{~mL}$ DCM, and 1.2 eq. A were used. It can be seen that $2 \mathrm{a}$ yield increased obviously when the catalyst dosage increased from 1.25 to $5 \mathrm{~mol} \%$, while $2 \mathrm{a}$ yield increased slightly with catalyst amount increasing from 5 to $10 \mathrm{~mol} \%$. Last but not least, the effect of reaction scale on the results was also investigated in detail when 1.2 eq. A (base on 1a), 1.2 eq. oxidants, $5 \mathrm{~mL} \mathrm{DCM}$, and $5 \mathrm{~mol} \%$ catalyst were used. The yield of $2 \mathrm{a}$ increased from $80 \%$ to $86 \%$ when the scale of $1 \mathrm{a}$ increased from 0.05 to $0.5 \mathrm{mmol}$. Remarkably, a 2a yield of $91 \%$ was obtained when 1a was in large amount of $5 \mathrm{mmol}$ (see Figure 2d). In conclusion, the optimum $2 \mathrm{a}$ yield of $91 \%$ was obtained when the reaction ran for $6 \mathrm{~h}$ at $25^{\circ} \mathrm{C}$ using $5 \mathrm{mmol} 1$-dodecyne, 1.2 eq. A, 1.2 eq. oxidant, $5 \%$ mol Mor-DalPhosAuOMs, and $5 \mathrm{~mL}$ DCM.
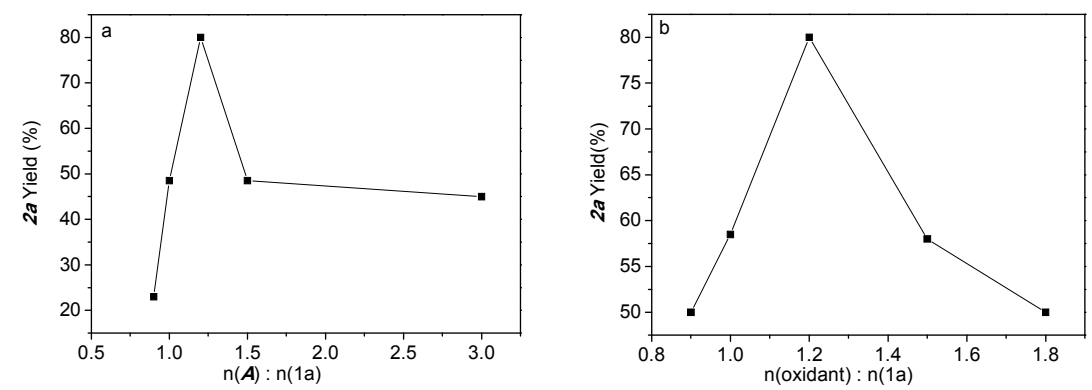

(a)

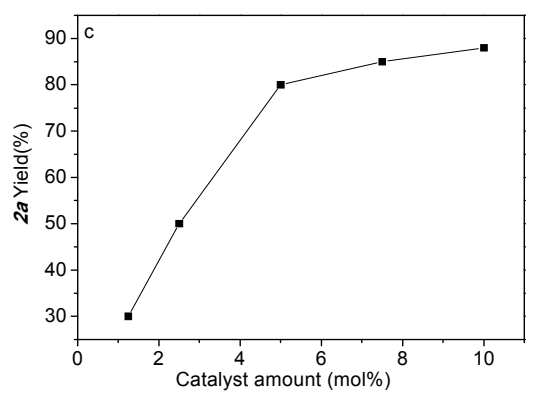

$(\mathbf{b})$

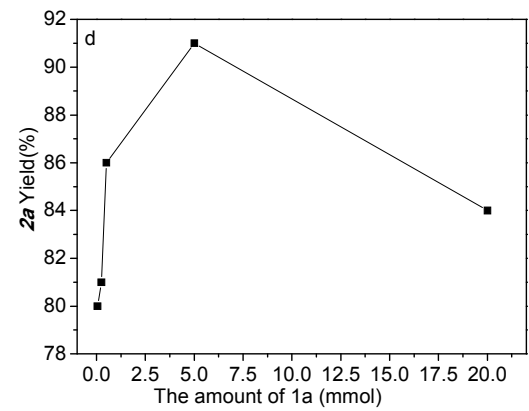

(c)

(d)

Figure 2. Effect of condition parameters on yield of intermediate product 2a; (a) Effect of $A$ amount on 2a yield, (b) Effect of 8-Me-quinoline $N$-oxides amount on 2a yield, (c) Effect of catalysts amount on 2a yield, (d) Effect of $1 \mathbf{a}$ amount on 2a yield. 


\subsection{One-Pot Synthesis of 2,4-Disubstituted Thiazoles}

On the basis of the optimized conditions and the previous work [11], the catalytic performance of the gold-catalyzed system was investigated in the one-pot synthesis of various 2,4-disubstituted thiazoles. It is worth mentioning that various thioamides were directly added to the as-obtained reaction mixture without isolation of intermediate product $\mathbf{2 a}$ (Figure 3). A range of thioamides were tested using 1-dodecyne as the alkyne component (entries 1-8). Thioamides with alkyl and phenyl groups underwent the reaction smoothly, affording 2,4-disubstituted thiazoles in acceptable-to-good yields (entries 1-5). Furan-2-thioamide and thiophene-2-thioamide gave the corresponding biheteroaryl products $4 \mathrm{f}$ and $4 \mathrm{~g}$ in relative low yield (entries 6 and 7). The reaction worked with 3-phenyl-thioacrylamide with the yield of $78 \%$ (entry 8 ). So, the as-obtained gold-catalyzed system exhibited high catalytic performance for 1-dodecyne and eight representative thioamides.

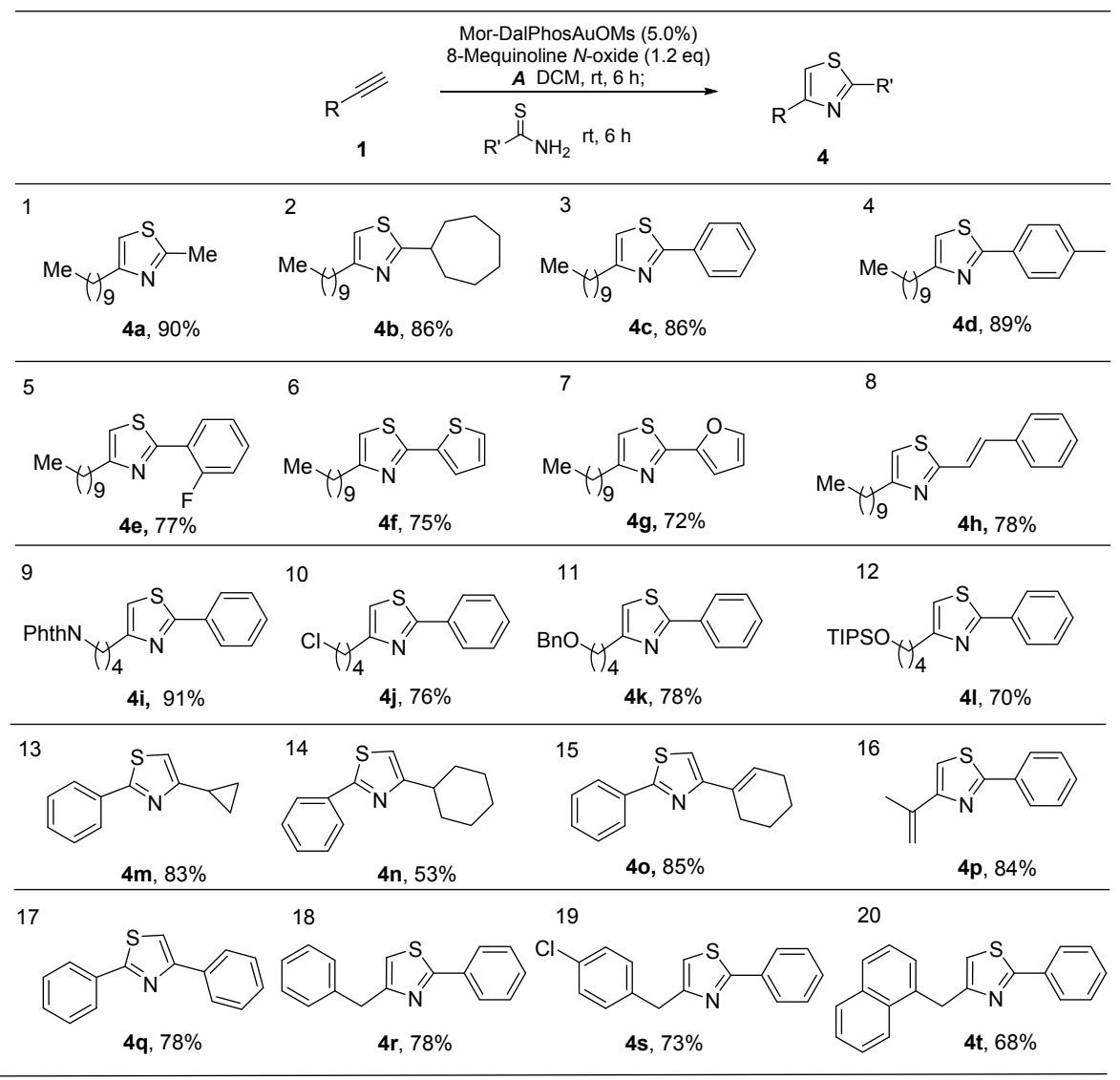

Figure 3. One-pot synthesis of 2,4-disubstituted thiazoles a . a Isolated yields; Reaction condition: 1-dodecyne, 5 mmol; A, 1.2 eq.; Oxidants, 1.2 eq.; thioamide, 1.2 eq.; DCM, $5 \mathrm{~mL}$; Room temperature $\left(25^{\circ} \mathrm{C}\right)$.

With respect to alkynes, linear aliphatic terminal alkynes with remote functional groups such as NPhth (entry 9), chloro (entry 10), BnO (entry 11), TIPS protected HO (entry 12) were suitable substrates. The reaction proceeded efficiently with cyclopropylacetylene (entry 13), while $4 \mathbf{n}$ was isolated in only 53\% yield using cyclohexylacetylene (entry 14). The alkyne with conjugated enone group did not appear to interfere with the thiazole formation (entries 15 and 16). Nevertheless, when a phenylacetylene was present (entry 17), the reaction still afforded an acceptable yield. Phenylallylene without (entry 18) and with (entries 19 and 20) an electron withdrawing group gave products in serviceable yields. Therefore, twenty kinds of 2,4-disubstituted thiazoles were synthesized smoothly by the as-obtained gold-catalyzed oxidation system. 


\subsection{Proposed Reaction Mechanism}

In view of the reported literature $[11,28]$ and the results we obtained (discussed above), a plausible mechanism was postulated, shown in Scheme 2. Using the 8-Methylquinoline $N$-oxide as oxidant, the alkyne can be oxidized into $\alpha$-oxo gold carbene $\mathbf{H}$ in the presence of gold complexes. The gold carbene $\mathbf{H}$ abstracted the anion of $\mathrm{OMs}^{-}$from $\mathbf{A}$, which resulted in the formation of methanesulfonic intermediate $\mathbf{I}$. With the split of cationic $\mathrm{Au}(\mathrm{I})$, methanesulfonic product $\mathbf{J}$ was generated and attacked by the thioamides. Then, internal dehydration took place in intermediate $\mathbf{K}$, which led to the production of 2,4-disubstituted thiazoles.

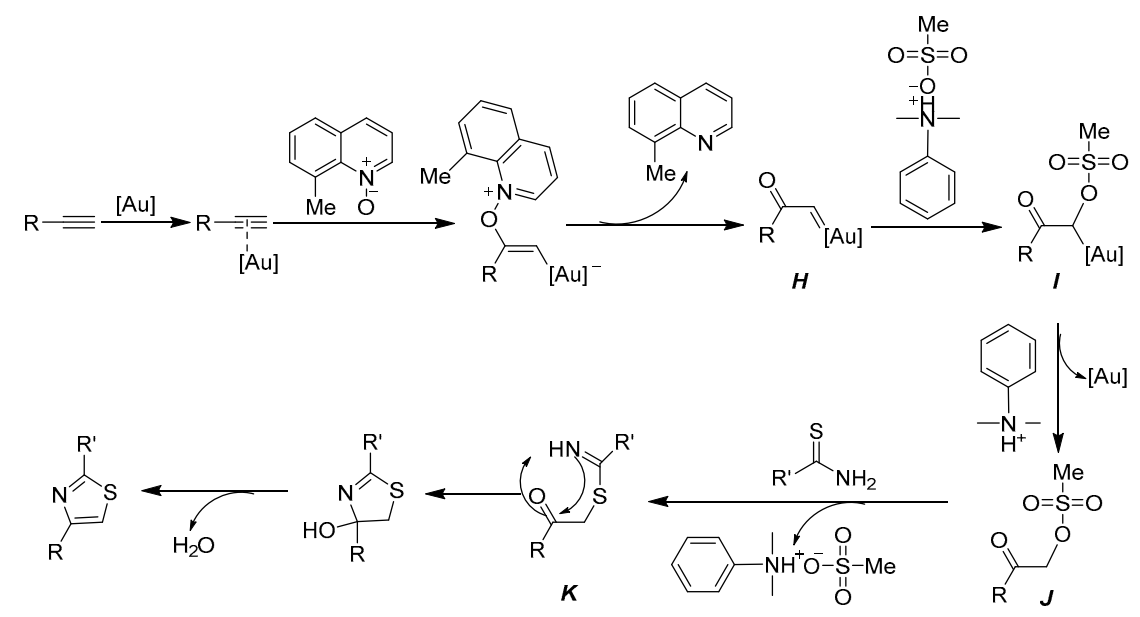

Scheme 2. Speculation of reaction mechanism.

\section{Experimental Section}

\subsection{Preparation and Characterization of Catalyst}

Homogeneous gold complexes were prepared by the ligand L (Scheme 3) and chloro(dimethylsulfide) gold(I) (AuCl.DMS), and then $\mathrm{Cl}^{-}$was abstracted from LAuCl by AgX. The synthetic and characterization procedures have been described in detail in previous reports $[11,27]$.

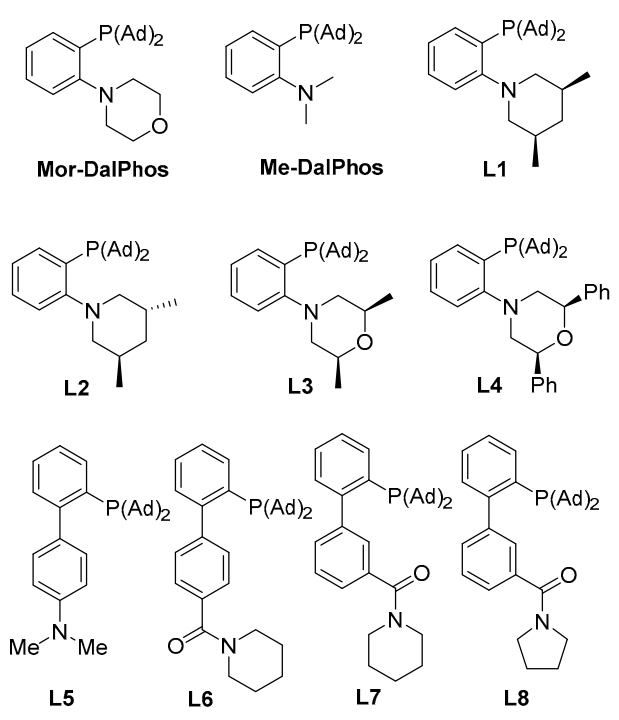

Scheme 3. The structure of ligands. 


\subsection{Preparations of Ammonium Sulfonates}

Typically, sulfonic acid $(25.0 \mathrm{mmol})$ was dropped to the solution of amines $(25.0 \mathrm{mmol})$ in alcohol $(50 \mathrm{~mL})$ over $0.5 \mathrm{~h}$. The reaction mixture was then stirred at room temperature for $0.5 \mathrm{~h}$ before the separation of precipitation. The obtained solids of ammonium sulfonate were further purified by recrystallizing in DCM. Their preparation is depicted in Scheme 4, and their similar structures are listed in Table 1.

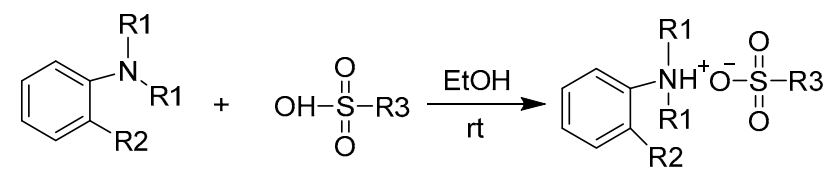

Scheme 4. The preparation of seven ammonium sulfonates.

\subsection{Catalytic Test}

\subsubsection{General Procedure for the Synthesis of Mesylates 2}

Typically, the terminal alkyne 1 ( $5 \mathrm{mmol})$, Mor-DalPhosAuOMs (0.188 g, $0.25 \mathrm{mmol}, 5 \mathrm{~mol} \%)$, 8-methylquinoline $\mathrm{N}$-oxide (3a; $0.96 \mathrm{~g}, 6 \mathrm{mmol})$, and $\mathbf{A}(6 \mathrm{mmol})$ were added to a three-necked flask containing $5 \mathrm{~mL}$ of dichloromethane. The reaction mixture was stirred at room temperature over $6 \mathrm{~h}$ before concentration under vacuum. The resulting residue was purified by silica gel flash chromatography (Starlab Scientific Co., Ltd, xian, Shanxi, China) to give 2.

\subsubsection{General Procedure for the One-Pot Synthesis of 2,4-Disubstituted Thiazoles 4}

Typically, to a three-necked flask containing $5 \mathrm{~mL}$ of dichloromethane, the terminal alkyne 1 ( $5.0 \mathrm{mmol}$ ), Mor-DalPhosAuOMs (0.188 g, $0.25 \mathrm{mmol}, 5 \mathrm{~mol} \%), 8$-methylquinoline $\mathrm{N}$-oxide (3a, $0.96 \mathrm{~g}$, $6 \mathrm{mmol})$, and $\mathbf{A}(6 \mathrm{mmol})$ were added in turn. The obtained mixture was stirred at room temperature for $6 \mathrm{~h}$, and then thioamide $(6 \mathrm{mmol})$ was further added. After another stirring for $6 \mathrm{~h}$, the mixture was concentrated under vacuum. The resulting crude reaction mixture was purified by silica gel flash chromatography to afford $4 .{ }^{1} \mathrm{H},{ }^{13} \mathrm{C}$ NMR spectra, Fourier Transform infrared spectroscopy (FTIR), and Electrospray Ionization (ESI) for products 4 are consistent with the literature [10,11].

\section{Conclusions}

In summary, seven kinds of low-acidity ammonium sulfonates were prepared and reacted with terminal alkynes for the generation of intermediate products. It was found that $\mathbf{A}$ exhibited the optimized 2a yield of $91 \%$ using Mor-DalPhosAuOMs as catalyst. In the one-pot synthesis of 2,4-disubstituted thiazoles, twenty kinds of products were successfully prepared in a large-scale and high yield. We anticipate this gold-catalyzed oxidation system could provide important reference values for the industrial preparation of 2,4-disubstituted thiazoles and their derivatives.

Acknowledgments: The authors acknowledge the financial supports from the National Natural Science Foundation of China (21003073, 21203093), the Natural Science Foundation of Jiangsu Province (BK20141388, BK20161481), Industry University Research Prospective Joint Research Project of Jiangsu Province (BY2016008-03), the Qing Lan Project of Jiangsu Province, the Academic Talents Training Project of Nanjing Institute of Technology, and the College students practice innovation training program of Jiangsu Province.

Author Contributions: W.G.D. and W.X.L. designed the experiments; W.G.D. analyzed the data and wrote the paper; L.H. performed the experiments.

Conflicts of Interest: The authors declare no conflict of interest. 


\section{References}

1. Banothu, J.; Vaarla, K.; Bavantula, R.; Crooks, P.A. Sodium fluoride as an efficient catalyst for the synthesis of 2,4-disubstituted-1,3-thiazoles and selenazoles at ambient temperature. Chin. Chem. Lett. 2014, 25, 172-175.

2. Siddiqui, N.; Arya, S.K.; Ahsan, W.; Azad, B. Diverse biological activities of Thiazoles: A Retrospect. Int. J. Drug Dev. Res. 2011, 3, 55-67.

3. Gautam, D.; Gautam, P.; Chaudhary, R.P. N-Methylpyridinium tosylate catalyzed green and efficient synthesis of some novel 2,4-disubstituted thiazoles and 4-thiazolidinones. Chin. Chem. Lett. 2012, 23, 1221-1224. [CrossRef]

4. Kushwaha, N.; Kushwaha, S.K.S.; Rai, A.K. Biological activities of thiadiazole derivatives: A review. Int. J. ChemTech Res. 2012, 4, 517-531.

5. Jin, Z. Muscarine, imidaozle, oxazole and thiazole alkaloids. Nat. Prod. Rep. 2013, 30, 869-915. [CrossRef] [PubMed]

6. Dondoni, A.; Marra, A. Thiazole-mediated synthetic methodology. Chem. Rev. 2004, 104, $2557-2599$. [PubMed]

7. Sadek, B.; Al-Tabakha, M.M.; Fahelelbom, K.M.S. Antimicrobial prospect of newly synthesized 1,3-thiazole derivatives. Molecules 2011, 16, 9386-9396. [PubMed]

8. Reddy, M.R.D.; Prasad, A.R.G.; Spoorthy, Y.N.; Ravindranath, L.R.K.R. Synthesis, characterization and antimicrobial activity of certain novel aryl hydrazone pyrazoline-5-ones containing thiazole moiety. Adv. Pharm. Bull. 2013, 3, 153-159. [PubMed]

9. Nielsen, D.S.; Hoang, H.N.; Lohman, R.; Diness, F.; Fairlie, D.P. Total synthesis, structure, and oral absorption of a thiazole cyclic peptide, Sanguinamide A. Org. Lett. 2012, 14, 5720-5723. [CrossRef] [PubMed]

10. Wu, G.; Wang, X.; Zhang, L.; Zhang, F.; Liu, X.; Liu, C. One-step synthesis of 2,4-disubstituted thiazoles in $\mathrm{Au}(\mathrm{I})$ Complex/Zinc salt catalytic system. Chin. J. Org. Chem. 2015, 35, 2537-2544.

11. Wu, G.; Zheng, R.; Nelson, J.; Zhang, L. One-step synthesis of methanesulfonyloxymethyl ketones via gold-catalyzed oxidation of terminal alkynes: A combination of ligand and counter anion enables high efficiency and a one-pot synthesis of 2,4-disubstituted thiazoles. Adv. Synth. Catal. 2014, 356, 1229-1234. [CrossRef]

12. Rudolpha, M.; Hashmi, A.S.K. Gold catalysis in total synthesis-An update. Chem. Soc. Rev. 2012, 41, 2448-2462. [CrossRef] [PubMed]

13. Alcaide, B.; Almendros, P.; Alonso, J.M. Gold-catalyzed cyclizations of alkynol-based compounds: synthesis of natural products and derivatives. Molecules 2011, 16, 7815-7843. [CrossRef] [PubMed]

14. Teles, J.H.; Brode, S.; Chabanas, M. Cationic gold(I) complexes: Highly efficient catalysts for the addition of alcohols to alkynes. Angew. Chem. Int. Ed. 1998, 37, 1415-1418. [CrossRef]

15. Hashmi, A.S.K.; Frost, T.M.; Bats, J.W. Highly selective gold-catalyzed arene synthesis. J. Am. Chem. Soc. 2000, 122, 11553-11554. [CrossRef]

16. Hashmi, A.S.K.; Schwarz, L.; Choi, J.H.; Frost, T.M. A new gold-catalyzed C-C bond formation. Angew. Chem. Int. Ed. 2000, 39, 2285-2288. [CrossRef]

17. Hashmi, A.S.K.; Weyrauch, J.P.; Frey, W.; Bats, J.W. Gold catalysis: Mild conditions for the synthesis of oxazoles from n-propargylcarboxamides and mechanistic aspects. Org. Lett. 2004, 6, 4391-4394. [CrossRef] [PubMed]

18. Weyrauch, J.P.; Hashmi, A.S.K.; Schuster, A.; Hengst, T.; Schetter, S.; Littmann, A.; Rudolph, M.; Hamzic, M.; Visus, J.; Rominger, F.; et al. Cyclization of propargylic amides: Mild access to oxazole derivatives. Chem. Eur. J. 2010, 16, 956-963. [CrossRef] [PubMed]

19. Kennedy-Smith, J.J.; Staben, S.T.; Toste, F.D. Gold(I)-catalyzed Conia-ene reaction of beta-ketoesters with alkynes. J. Am. Chem. Soc. 2004, 126, 4526-4527. [CrossRef] [PubMed]

20. Staben, S.T.; Kennedy-Smith, J.J.; Toste, F.D. Gold-catalyzed 5-endo-dig carbocyclization of acetylenic dicarbonyl compounds. Angew. Chem. Int. Ed. 2004, 43, 5350-5352. [CrossRef] [PubMed]

21. Jaimes, M.C.B.; Rominger, F.; Pereira, M.M.; Carrilho, R.M.B.; Carabineiro, S.A.C.; Hashmi, A.S.K. Highly active phosphite gold(I) catalysts for intramolecular hydroalkoxylation, enyne cyclization and furanyne cyclization. Chem. Commun. 2014, 50, 4937-4940. [CrossRef] [PubMed]

22. Nevado, C.; Echavarren, A.M. Intramolecular hydroarylation of alkynes catalyzed by platinum or gold: Mechanism and endo selectivity. Chem. Eur. J. 2005, 11, 3155-3164. [CrossRef] [PubMed] 
23. Ferrer, C.; Echavarren, A.M. Gold-catalyzed intramolecular reaction of indoles with alkynes: Facile formation of eight-membered rings and an unexpected allenylation. Angew. Chem. Int. Ed. 2006, 45, 1105-1109. [CrossRef] [PubMed]

24. Antoniotti, S.; Genin, E.; Michelet, W.; Genet, J.P. Highly efficient access to strained bicyclic ketals via gold-catalyzed cycloisomerization of bishomopropargylic diols. J. Am. Chem. Soc. 2005, 127, 9976-9977. [CrossRef] [PubMed]

25. Buzas, A.; Gagosz, F. Gold(I)-catalyzed formation of 4-alkylidene-1,3-dioxolan-2-ones from propargylic tert-butyl carbonates. Org. Lett. 2006, 8, 515-518. [CrossRef] [PubMed]

26. Mizushima, E.; Hayashi, T.; Tanaka, M. Au(I)-catalyzed highly efficient intermolecular hydroamination of alkynes. Org. Lett. 2003, 5, 3349-3352. [CrossRef] [PubMed]

27. Wang, Y.; Wang, Z.; Li, Y.; Wu, G.; Cao, Z.; Zhang, L. A general ligand design for gold catalysis allowing ligand-directed anti-nucleophilic attack of alkynes. Nat. Commu. 2014, 5, 3470. [CrossRef] [PubMed]

28. Ji, K.; Zhao, Y.; Zhang, L. Optimizing P,N-Bidentate ligands for oxidative gold catalysis: Efficient intermolecular trapping of $\alpha$-oxo gold carbenes by carboxylic acids. Angew. Chem. Int. Ed. 2013, 52, 6508-6512. [CrossRef]

29. Luo, Y.; Ji, K.; Li, Y.; Zhang, L. Tempering the reactivities of postulated $\alpha$-oxo gold carbenes using bidentate ligands: Implication of tricoordinated gold intermediates and the development of an expedient bimolecular assembly of 2,4-disubstituted oxazoles. J. Am. Chem. Soc. 2012, 134, 17412-17415. [CrossRef] [PubMed]

30. Khin, C.; Hashmi, A.S.K.; Rominger, F. Gold(I) complexes of P,N ligands and their catalytic activity. Eur. J. Inorg. Chem. 2010, 7, 1063-1069. [CrossRef]

(C) 2016 by the authors; licensee MDPI, Basel, Switzerland. This article is an open access article distributed under the terms and conditions of the Creative Commons Attribution (CC-BY) license (http:/ / creativecommons.org/licenses/by/4.0/). 